Research Article

\title{
Strain Incremental Adjustment Method of Cable Force of Composite Saddle Anchor Span of Single-Tower Single-Span Ground-Anchored Suspension Bridge
}

\author{
Long Yu $\mathbb{D}^{1},{ }^{1}$ Wei Xu $\mathbb{D}^{1},{ }^{1}$ Da-bing Zhang $\mathbb{D}^{2},{ }^{2}$ Xu-ming $M a \mathbb{D},{ }^{2}$ and Yong-hong $W u \mathbb{D}^{1}$ \\ ${ }^{1}$ Faculty of Architectural Engineering, Kunming University of Science and Technology, Kunming, Yunnan 650500, China \\ ${ }^{2}$ China Railway Bridge Science Research Institute Co., Ltd., Wuhan, Hubei 430000, China
}

Correspondence should be addressed to Long Yu; 514633006@qq.com and Yong-hong Wu; 496567227@qq.com

Received 11 October 2021; Revised 9 November 2021; Accepted 10 November 2021; Published 30 November 2021

Academic Editor: Gan Feng

Copyright ( $\odot 2021$ Long Yu et al. This is an open access article distributed under the Creative Commons Attribution License, which permits unrestricted use, distribution, and reproduction in any medium, provided the original work is properly cited.

\begin{abstract}
To improve the efficiency of cable force adjustment of composite saddle anchor span of single-tower single-span ground-anchored suspension bridge, a strain incremental adjustment method is proposed. The analytical calculation model is established according to the relative spatial position of the cable strand and the saddle groove of the composite saddle, and the target cable force of the cable strands is calculated by the target position of the composite saddle in the cable-stayed bridge and construction phases. Considering the coupling relationship between the cable strand and the composite saddle, the calculation formula of the change in main span main cable force and anchor span cable force after the adjustment of a single cable strand is derived. Based on the condition of equilibrium of forces along the slip surface of the composite saddle, the slip amount of composite saddle after a round of cable strand adjustment is obtained, then the adjustment amount of actual construction of the cable strands is also obtained through the strain incremental adjustment method. With the help of a numerical simulation platform, the calculation program of the cable force adjustment of composite saddle anchor span is established by an iterative solution method. In this paper, taking the Jinsha River Bridge at Hutiao Gorge as a research object, the adjustment of cable force of composite saddle anchor span is analyzed and calculated. The research results indicate that the calculated cable force is obtained by the strain incremental adjustment method, and it is similar to the measured cable force. The cable strand adjustment and optimization method avoids excessive repeated stretching and relaxation of a single cable strand in the process of multiple rounds of cable strand adjustment and reduces the amount of construction adjustment. This method can effectively reduce the times of cable strand adjustment and improve the efficiency of adjusting the anchor span cable force.
\end{abstract}

\section{Introduction}

The single-tower single-span ground-anchored suspension bridge has only one tower, and the other end of the main cable is anchored on the tunnel anchor bolt after passing the composite saddle structure. This type of bridge is fully adapted to the steep terrain of the mountain, reducing a bridge tower and a side span. Compared with the common saddle of the multitower suspension bridge, the composite saddle on the single-tower suspension bridge has the functions of both tower saddle and splay saddle. The change of the saddle position will lead to the change of the main cable shape of the main span and the anchor span cable force. The anchor span of the composite saddle is controlled by the cable strand tension [1-3], and the accuracy of cable force adjustment will affect the reliability of the overall structure of the suspension bridge [4-9]. The composite saddle is directly connected with the main cable of the main span. Compared with the force at both ends of the splay saddle, the force at both ends of the composite saddle is greater, and the requirements of the adjustment accuracy of the cable forces are higher. Therefore, it is still difficult to adjust the anchor span cable force of the composite saddle quickly and accurately.

In the process of cable strand construction adjustment, the difference between the measured cable force and the 
target cable force is usually used to determine the adjustment amount [10]. This method does not take into account the coupling relationship between the cable strand and the cable saddle. After the adjustment of a single cable strand, the change of the cable force will change the position of the cable saddle. When the position of the endpoint of the cable strand changes, the cable force of the adjusted cable strand cannot reach the target cable force through a round of adjustment, and the efficiency and the accuracy of cable strand adjustment are greatly reduced. At present, there is little research on composite saddle structure, which is basically in the phase of the model test [11]. For the research of the adjustment method of the anchor span cable force, most of them take the splay saddle structure as the research object. Through the analysis of the spatial geometric relationship of cable strands [12-14], the cable force of the splay saddle at the target position is obtained. Considering the influence of temperature on cable strand tension, the cable strand tension adjustment method under the influence of temperature change is obtained [15]. For the measured cable force, boundary constraints, stiffness, and material characteristics of cable strand are mainly considered [10, 16-20]. The accurately measured frequency is obtained by the energy method and the frequency method, to improve the measurement accuracy of cable force.

To quickly and accurately control the composite saddle anchor span, this paper establishes the calculation method of strain incremental adjustment of composite saddle anchor span of single-tower single-span ground-anchored suspension bridge and develops the numerical simulation program with the help of programming software [21-23]. According to the relative spatial position of the cable strand and the composite saddle, the target cable force of the composite saddle at the target position is obtained. The coupling relationship between the cable strand and the composite saddle in the cable strand adjustment phase is analyzed, and the actual adjustment amount of the cable strand is obtained by the strain increment method, so that the purpose of accurate cable strand adjustment can be realized through a round of adjustment theoretically. The method is applied to the process of the cable strand adjustment calculation, and the practicability of the method is verified by comparing the field measured data.

\section{Structure of Composite Saddle and Characteristics of Anchor Span Cable Strand}

2.1. Structural Characteristics of the Composite Saddle. The composite saddle is a unique structure of a single-tower single-span ground-anchored suspension bridge. It is located on the buttress platform between the main span and the anchor span and plays the role of supporting, deflecting, and dispersing the main cable. Its structure is shown in Figure 1. The composite saddle changes the span of the main span and the anchor span through the activity of the bottom roller shaft, to balance the force at both ends of the saddle. Compared with the deflection angle of the main cable and the cable strand of the traditional rock shaft splay saddle, the deflection angle of the main cable and the anchor span cable strand at both ends of the composite saddle is larger, and the radial force of the main cable and the cable strand is larger.

\subsection{Distribution Characteristics of Anchor Span Cable Strand.} The cable strand is a spatial curve in the saddle groove of the composite saddle. Through the top and side view of the cable saddle, the deflection of the cable strand can be divided into horizontal bending and vertical bending. The horizontal bending curve is an arc segment with a small angle on a circle, and the vertical bending curve is an arc segment with a multisegment radius gradually decreasing. As shown in Figure 2, the cable strand passes through the starting point of vertical bending (Point $a$ ), the fixed point (Point $b$ ), the starting point of horizontal bending (Point $c$ ), the endpoint of horizontal bending (Point $d$ ), and the endpoint of vertical bending (Point $e$ ) in turn in the saddle groove. The cable strand starts vertical bending deflection first and then horizontal bending deflection. The cable strand ends the horizontal bending deflection first, then the vertical bending deflection, and finally be pulled to the position of the corresponding anchor point on the anchor surface. The composite saddle slides in the longitudinal direction along the horizontal plane of the buttress, which changes the tangent point of the cable strand at the anchor span side in the saddle groove, resulting in the changes of the coordinates of Point e, the unstressed length of the suspended segment of the cable strand and the cable force of the cable strand.

\section{Calculation Principle of Anchor Span Cable Strand Adjustment}

Basic assumptions, (1) the cable strand is an ideal flexible cable with small deformation, which satisfies Hooke's law, and the section deformation can be ignored. (2) The deformation of the composite saddle is very small and can be ignored in the process of cable force adjustment. (3) The cable strand does not slide relatively in the saddle groove. (4) In the process of cable force adjustment, the stiffness of the main tower is large enough, and the offset is small, and the change of the main span caused by it can be ignored.

\subsection{Basic Principle of Anchor Span Cable Strand Adjustment.} The anchor span is controlled by the cable strand tension. When the cable force of each cable strand can reach the target cable force, the composite saddle can slide to the target position through the cable force adjustment. Before the cable force adjustment, the measured cable force is obtained by field measurement, and the theoretical target cable force is calculated by the analytical method. The difference of cable force is calculated by the measured cable force and the target cable force, and then the actual adjustment of the cable strand can be obtained by iterative solution.

According to the relative spatial position of cable strands in the cable-stayed bridge state, the horizontal bending and the vertical bending angles of cable strands are calculated, then the unstressed length from Point $b$ to the anchor point of cable strands in the anchor span is calculated. The 


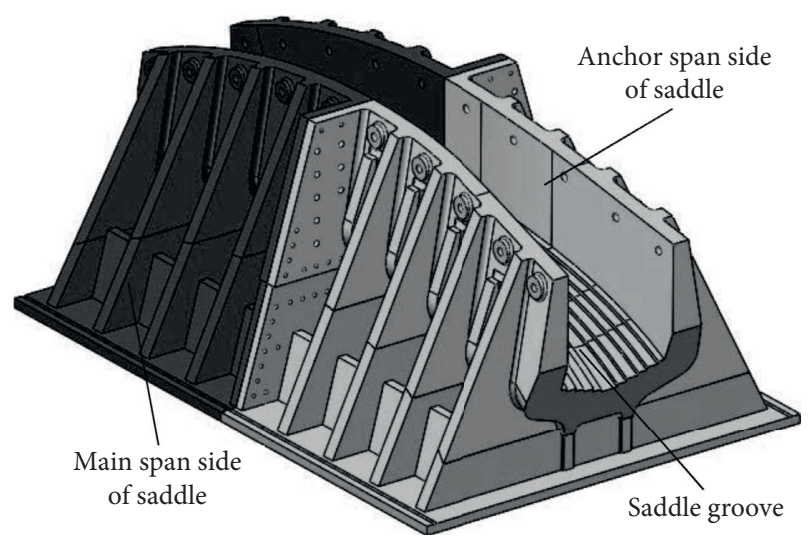

Figure 1: Structural drawing of the composite saddle.

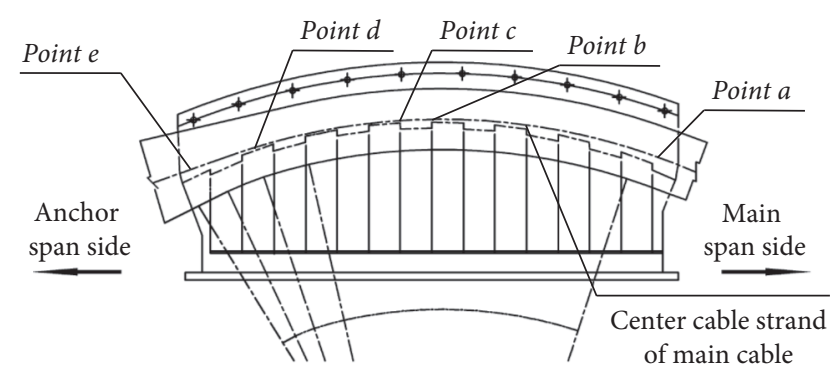

FIgURE 2: Side view of the composite saddle.

unstressed length represents the original length of the cable strand when there is no force on the cable strand. There is a certain offset between the position of the composite saddle in the construction phase and that in the cable-stayed bridge phase. According to the unstressed length of the cable strand and the target offset of the composite saddle, the target cable force can be calculated. By comparing the target cable force with the measured cable force, the initial value of the cable strand adjustment can be calculated by using the pitch method [10]. Through the difference of cable force and the longitudinal tensile stiffness of cable strand, the rotation direction and the number of turns of the bolt are calculated by the pitch method.

Because the composite saddle will slip during cable strand adjustment, the actual strain after cable strand adjustment deviates from the calculated value, and the remaining cable strands will produce strain increment due to the slide of the composite saddle. The strain incremental adjustment method can obtain the adjustment amount of actual construction by superimposing the adjustment amount of change of multiple rounds of cable strand adjustment. According to the initial value of cable strand adjustment, a round of adjustment of all cable strands can be calculated. Considering the coupling relationship between the cable strand and the composite saddle, the strain increment of all cable strands after adjustment of each cable strand can be calculated, and then the change of actual adjustment amount is obtained. Through multiple rounds of cycle iterative calculation, the cable forces of all cable strands approach the target cable force. Through superimposing the cable force adjustment amount caused by multiple rounds of strain increment of each cable strand, the adjustment amount of actual construction of cable strand can be obtained.

3.2. Calculation of Horizontal and Vertical Bending Angles. According to the spatial trend of the cable strand in the saddle groove and the cable strand of the suspended segment, the analytical calculation model of cable force of cable strand is established. In the process of calculating the target cable force, the problem of calculating the deflection angle of the cable strand will be encountered. According to the spatial distribution of the cable strand in the saddle groove, the spatial curve of the cable strand is divided into horizontal bending and vertical bending. Under the horizontal bending coordinate system, the horizontal bending angle of the cable strand can be calculated. The approximate calculation method of horizontal bending angle $\theta$ is shown in Figure 3 .

In the figure, $A, B$, and $C$ are Point $c$, Point $d$, and the anchor point, and $R_{0}$ is the horizontal bending radius. $\varphi$ and $x_{1}$ are the auxiliary angle and the auxiliary line. The longitudinal direction of the bridge is the $X$-axis, the transverse direction of the bridge is the $Y$-axis, and the vertical direction is the $Z$-axis. $\Delta x_{0}$ and $\Delta y_{0}$ are the difference of the coordinates between Point $c$ and the anchor point. It can be seen from Figure 3, $\varphi$ can be written as

$$
\phi=\arctan \frac{\Delta y_{0}}{\Delta x_{0}} .
$$

Compared with the anchor span, the offset caused by the angle of the cable strand is very small, and $\varphi$ is approximately equal to $\theta . x_{1}$ can be written as

$$
x_{1}=R_{0} \tan \frac{\phi}{2} \text {. }
$$

The corrected horizontal bending angle $\theta$ is

$$
\theta=\arctan \frac{\Delta y_{0}}{\Delta x_{0}-x_{1}} .
$$

Similarly, according to the coordinates of Point $a$ and the anchor point under the vertical bending plane, the radii of different circular arc segments are brought in to calculate the vertical bending angle by the above method. The circular arc segment where Point $e$ is located is judged by the calculated vertical bending angle, and the radius of the circular arc segment is the same as that used in calculating the vertical bending angle, then the calculated vertical bending angle is accurate. According to the intersection coordinates between the circular arc segments, the coordinates of Point $e$ are calculated through the vertical bending angle and the radius of the circular arc segment. $\theta_{H i}$ and $\theta_{V i}$ represent horizontal and vertical bending angles of the $i$ th cable strand.

\subsection{Calculation of a Round of Cable Strand Adjustment.} Under the action of uniformly distributed load along the cable length, the shape of the suspension segment is catenary [24-34]. The cable segment from Point e to the anchor point 


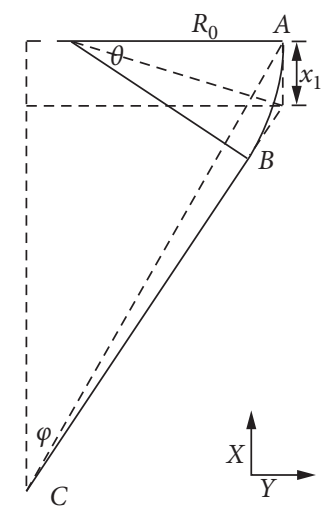

FIgURE 3: Calculation of horizontal bending angle of anchor span cable strand.

is catenary, while the main cable shape of the main span in the cable-stayed bridge state is segmented catenary with concentrated force, and the analytical solution of the catenary is

$$
\begin{aligned}
& l=\frac{H S_{0}}{E A}+\frac{H}{w}\left\{\ln \left[V+\sqrt{H^{2}+V^{2}}\right]-\ln \left[V-W+\sqrt{H^{2}+(V-W)^{2}}\right]\right\} \\
& h=\frac{W S_{0}-2 V S_{0}}{2 E A}-\frac{1}{w}\left[\sqrt{H^{2}+V^{2}}-\sqrt{H^{2}+(V-W)^{2}}\right]
\end{aligned}
$$

where $W=w S_{0}, w$ is the self-weight intensity, and $l$ and $h$ are the span and the elevation difference of both endpoints. $S_{0}$ is the unstressed length, and $H$ and $V$ are the horizontal and vertical force at the cable end. $E$ and $A$ are the elastic modulus and the section area of the suspension segment.

Considering the influence of temperature on the unstressed length and the self-weight intensity of the cable segment, the catenary formula at a certain temperature can be derived by replacing $S_{0 t}$ and $w_{0}$ :

$$
\begin{aligned}
& S_{0 t}=(1+\lambda \Delta t) S_{0}, \\
& w_{0}=\frac{w}{1+\lambda \Delta t},
\end{aligned}
$$

where $S_{0 t}$ and $w_{0}$ are the unstressed lengths and the selfweight intensity of the suspension segment at a certain temperature. $\lambda$ is the coefficient of temperature expansion, and $\Delta t$ is the temperature difference.

Segmented catenary with concentrated force is as shown in Figure 4. The horizontal force $H_{i}$ and the vertical force $V_{i}$ at the left end of the $i$ th segment are

$$
\begin{aligned}
& H_{i}=H, \\
& V_{i}=V_{i-1}-w S_{0, i-1}-P_{i-1}=V-\sum_{j=1}^{i-1} w S_{0 j}-\sum_{j=1}^{i-1} P_{j},
\end{aligned}
$$

where $P_{i}$ is the concentrated force of the $i$ th sling on the main cable. $S_{0 i}$ is the unstressed length of the $i$ th suspension cable, and $S_{0, i-1}$ is the unstressed length of the $(i-1)$ th suspension cable. Through bringing in the above formula, the analytical solution of the segmented catenary is

$$
\begin{aligned}
& l=\frac{H}{E A} \sum_{i=1}^{n} S_{0 i}+\frac{H}{w} \sum_{i=1}^{n}\left\{\ln \left[V_{i}+\sqrt{H^{2}+V_{i}^{2}}\right]-\ln \left[V_{i}-w S_{0 i}+\sqrt{H^{2}+\left(V-w S_{0 i}\right)^{2}}\right]\right\} \\
& h=\frac{1}{2 E A} \sum_{i=1}^{n}\left(w S_{0 i}^{2}-2 V S_{0 i}\right)-\frac{1}{w} \sum_{i=1}^{n}\left[\sqrt{H^{2}+V_{i}^{2}}-\sqrt{H^{2}+\left(V_{i}^{2}-w S_{0 i}\right)^{2}}\right] .
\end{aligned}
$$




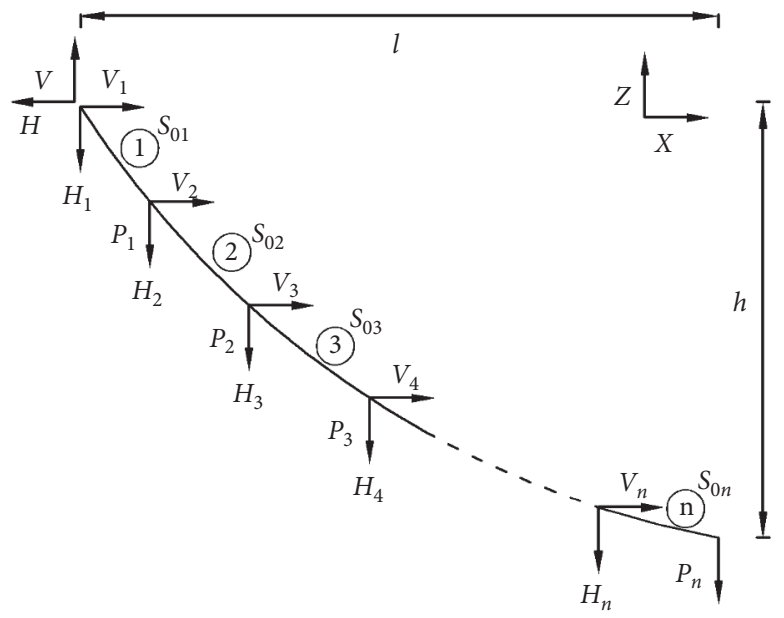

FIGURE 4: Segmented catenary with concentrated force. $V$ is

For the above formula, the complete differential of $H$ and

$$
\left[\begin{array}{l}
\mathrm{d} l \\
\mathrm{~d} h
\end{array}\right]=\left[\begin{array}{ll}
\frac{\partial l}{\partial H} & \frac{\partial l}{\partial V} \\
\frac{\partial h}{\partial H} & \frac{\partial h}{\partial V}
\end{array}\right]\left[\begin{array}{l}
\mathrm{d} H \\
\mathrm{~d} V
\end{array}\right]=R\left[\begin{array}{l}
\mathrm{d} H \\
\mathrm{~d} V
\end{array}\right]
$$

where $R$ is the flexibility matrix, $\mathrm{d} l$ and $\mathrm{d} h$ are the differential form of span $l$ and elevation difference $h$. The stiffness matrix is $K=R^{-1}$.

According to the checking calculation, the change of sling force caused by the slide of the composite saddle has little impact on the horizontal component of main cable tension in the whole process of cable strand adjustment construction, then the sling cable force can be regarded as a fixed value. When the slip amount of composite saddle is $\Delta S$, the amount $\Delta H$ and $\Delta V$ of change of cable force of the main span is

$$
\left[\begin{array}{c}
\Delta H \\
\Delta V
\end{array}\right]=K\left[\begin{array}{c}
\Delta S \\
0
\end{array}\right] .
$$

After the ith cable strand adjustment, the slip amount of the composite saddle is $\Delta S_{i}$. The component of change of the main cable tension of the main span along the horizontal direction is $\Delta H_{i}$.

As the span from Point e to the anchor point is short, and the cable force is large, the suspended segment of the cable strand can be calculated as a straight line, and its spatial position is as shown in Figure 5. $O$ is the anchor point, and $D$ is Point e. The plane $X O Z$ is the vertical bending plane, and the plane $X O Y$ is the horizontal bending plane. The angle $\alpha$ between the $O D$ and its projection on the plane $X O Y$ and the angle $\beta$ between the projection and the $X$-axis can be calculated. Then, the target cable force and the unstressed length $S_{0 i}$ under the target slip amount can be calculated, and the adjustment amount $\Delta l_{i}$ of cable strand by pitch method can be calculated. The coordinate difference $\Delta x, \Delta y$, and $\Delta z$ between Point $e$ and the anchor point at the current position can be obtained.

When adjusting the $i$ th cable strand of anchor span, the sum $\Delta F_{i}$ of the amount of change of the cable force along the sliding surface is

$$
\begin{aligned}
& \Delta F_{i}=E A \frac{\Delta l_{i}}{S_{0 i}} \cos \alpha_{i} \cos \beta_{i}-E A \sum_{j=1}^{n}\left(\frac{\Delta \varepsilon_{j}}{S_{0 j}} \cos \alpha_{j} \cos \beta_{j}\right), \\
& \Delta \varepsilon_{j}=\sqrt{\Delta x_{j}^{2}+\Delta y_{j}^{2}+\Delta z_{j}^{2}}-\sqrt{\left(\Delta x_{j}-\Delta S_{i}\right)^{2}+\Delta y_{j}^{2}+\Delta z_{j}^{2}},
\end{aligned}
$$

where $\Delta \varepsilon_{j} / S_{0 j}$ is the strain increment, and the angle $\alpha_{i}$ between the $O D$ of the $i$ th cable strand and its projection on the plane $X O Y$ and the angle $\beta_{i}$ between the projection and the $X$-axis can be calculated. During the adjustment of the $i$ th strand, the process can be understood in two parts: the change of the cable force of the $i$ th strand and the change of the cable force of all strands. In equation (10), the first half on the right of the equal sign represents the cable force change of the $i$ th cable strand after it is adjusted according to the initial adjustment, and the second half represents the sum of the cable force changes of all cable strands after the $i$ th cable strand is adjusted. $\Delta \varepsilon_{j}$ is the deformation after adjusting the $j$ th cable strand in equation (11).

$\Delta F_{i}=\Delta H_{i}$ is obtained by the equilibrium relationship, and the slip amount $\Delta S_{i}$ can be calculated by iterative solution. The updated coordinates are $\Delta x_{j}^{\prime}=\Delta x_{j}-\Delta S_{i}$, $\Delta y_{j}^{\prime}=\Delta y_{j}$ and $\Delta z_{j}^{\prime}=\Delta z_{j}$, and $(i+1)$ th adjustment amount is

$$
\Delta l_{i+1}^{\prime}=\Delta l_{i+1}-\sqrt{\Delta x_{i+1}^{2}+\Delta y_{i+1}^{2}+\Delta z_{i+1}^{2}}+\sqrt{\Delta x_{i+1}^{\prime 2}+\Delta y_{i+1}^{\prime 2}+\Delta z_{i+1}^{\prime 2}}
$$




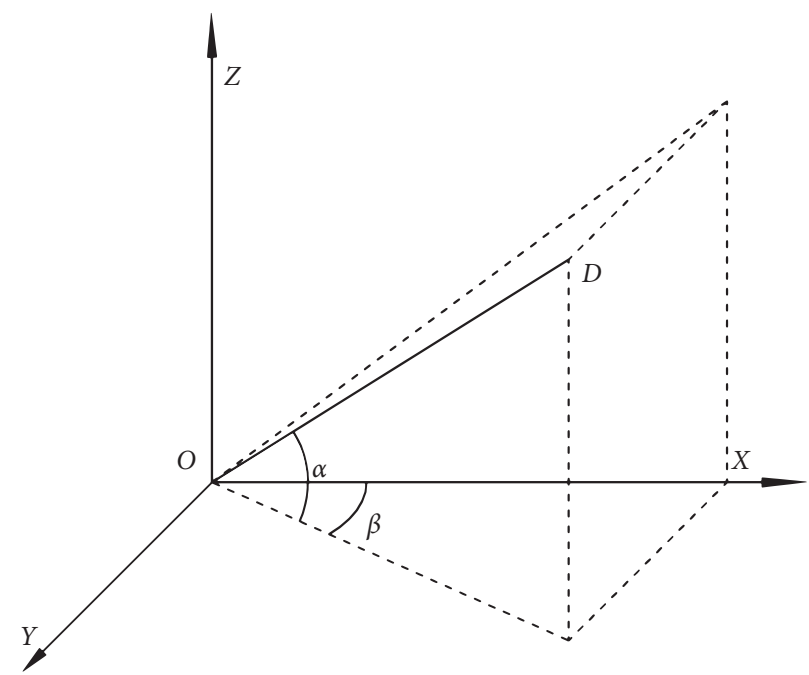

FIGURE 5: Spatial position of the cable strand.

The updated main span is $l_{i+1}=l_{i}+\Delta S_{i}$, and $l_{i}$ is the main span after adjusting the $i$ th strand. All cable strands are cycled. After a round of cable strand adjustment, the sum of the slip amount is

$$
\Delta S=\sum_{i=1}^{n} \Delta S_{i}
$$

When the composite saddle slides to the current position, the force of each cable strand can be calculated. The force is

$$
T_{i}^{\prime}=T_{i}+E A \frac{\Delta l_{i}-\sqrt{\Delta x_{i}^{2}+\Delta y_{i}^{2}+\Delta z_{i}^{2}}+\sqrt{\left(\Delta x_{i}-\Delta S\right)^{2}+\Delta y_{i}^{2}+\Delta z_{i}^{2}}}{S_{0 i}},
$$

where $T_{i}$ is the measured cable force and $T_{i}^{\prime}$ is calculated by the strain increment of the cable strand. The initial cable force is updated to $T_{i}^{\prime}$ by the above formula. The current composite saddle position is regarded as the initial position, $\Delta x_{i}^{\prime}=\Delta x_{i}-\Delta S, \Delta y_{i}^{\prime}=\Delta y_{i}$, and $\Delta z_{i}^{\prime}=\Delta z_{i}$, and the main span is $l^{\prime}=l+\Delta S$. The initial adjustment amount of each strand caused by strain increment is updated to

$$
\Delta l_{i}^{\prime}=\sqrt{\Delta x_{i}^{2}+\Delta y_{i}^{2}+\Delta z_{i}^{2}}-\sqrt{\left(\Delta x_{i}-\Delta S\right)^{2}+\Delta y_{i}^{2}+\Delta z_{i}^{2}} .
$$

The difference $\Delta T_{i}$ between the current cable force and the target cable force is calculated circularly through the above formula. When $\Delta T_{i}$ meets the accuracy requirements, the initial adjustment amount of each cable strand in the overall cycle phase is superimposed to obtain the actual adjustment amount of each anchor span cable strand. When all cable strands are adjusted for $m$ rounds, the difference between the calculated cable forces and the target cable forces of all cable strands can meet the accuracy requirements, and the adjustment amount of the actual construction of the $i$ th cable strand is

$$
\Delta L_{i}=\sum_{j=1}^{m} \Delta l_{i j}^{\prime}
$$

where $\Delta l_{i j}^{\prime}$ is the adjustment amount of the $i$ th cable strand of the $j$ th round of cable strand adjustment.

\section{Adjustment Method of Anchor Span Cable Strand and Its Program Implementation}

4.1. Calculation Process of Target Cable Force. According to the position of the composite saddle and the spatial position of the cable strand in the saddle groove under the cablestayed bridge phase, the analytical calculation model of the cable strand is established with $18^{\circ} \mathrm{C}$ as the reference temperature, and the unstressed length of all cable strands from Point $b$ to the anchor point is calculated. The process is as shown in Figure 6(a), which can be applied to calculate the cable force at any construction phase. According to the slip amount of composite saddle, the coordinates of Point $a$, the span, and the elevation difference from Point e to the anchor point can be calculated, and the anchor span cable force at the current position of the composite saddle is calculated by using the catenary formula. This anchor span cable force is the theoretical target cable force, and it is the cable force at the anchor surface end of the cable strand. When the composite saddle slides to the target position, this method can also be used to calculate the cable force of each cable strand. For example, the pre-bias position of the composite saddle is known when there is no external load on the main cable, and the target cable force at the anchor end can be calculated according to the pre-bias position. The process is as shown in Figure 6(b), where the tangent angle represents the angle between the tangent at point $e$ and the $X$-axis.

In the process of calculating the length of the spatial curve of the cable strand in the saddle groove, the stressed length is approximately calculated by dividing the interpolation points. The stressed length represents the actual length of the cable 


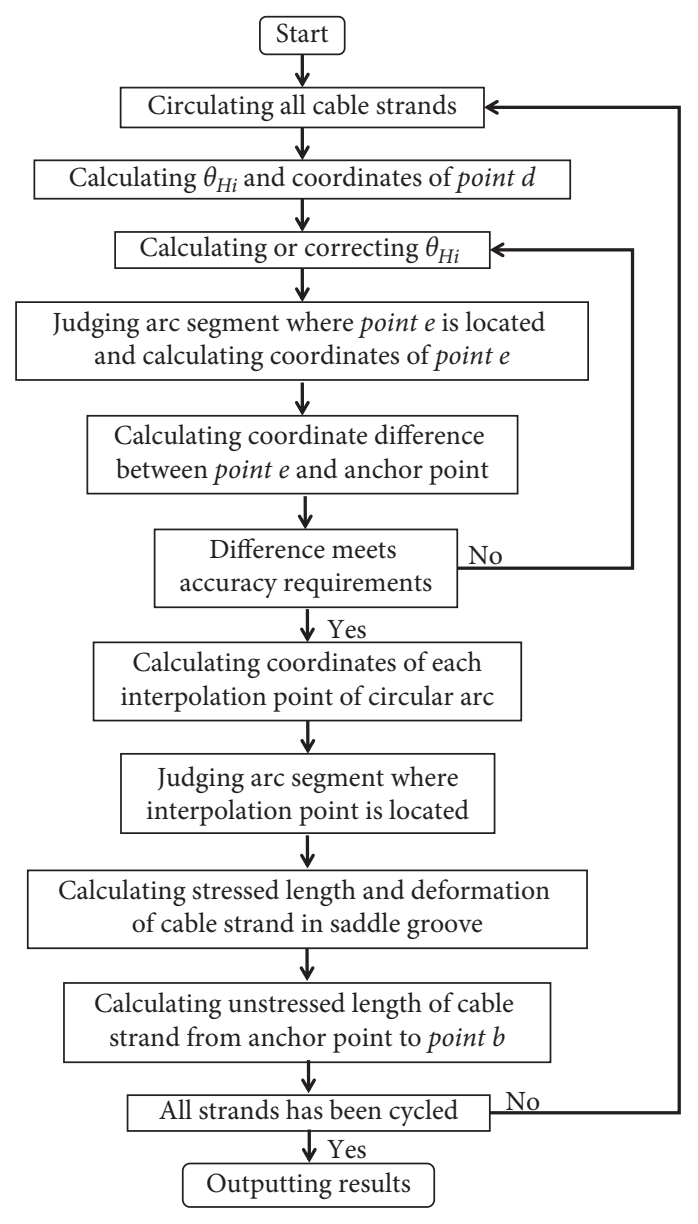

(a)

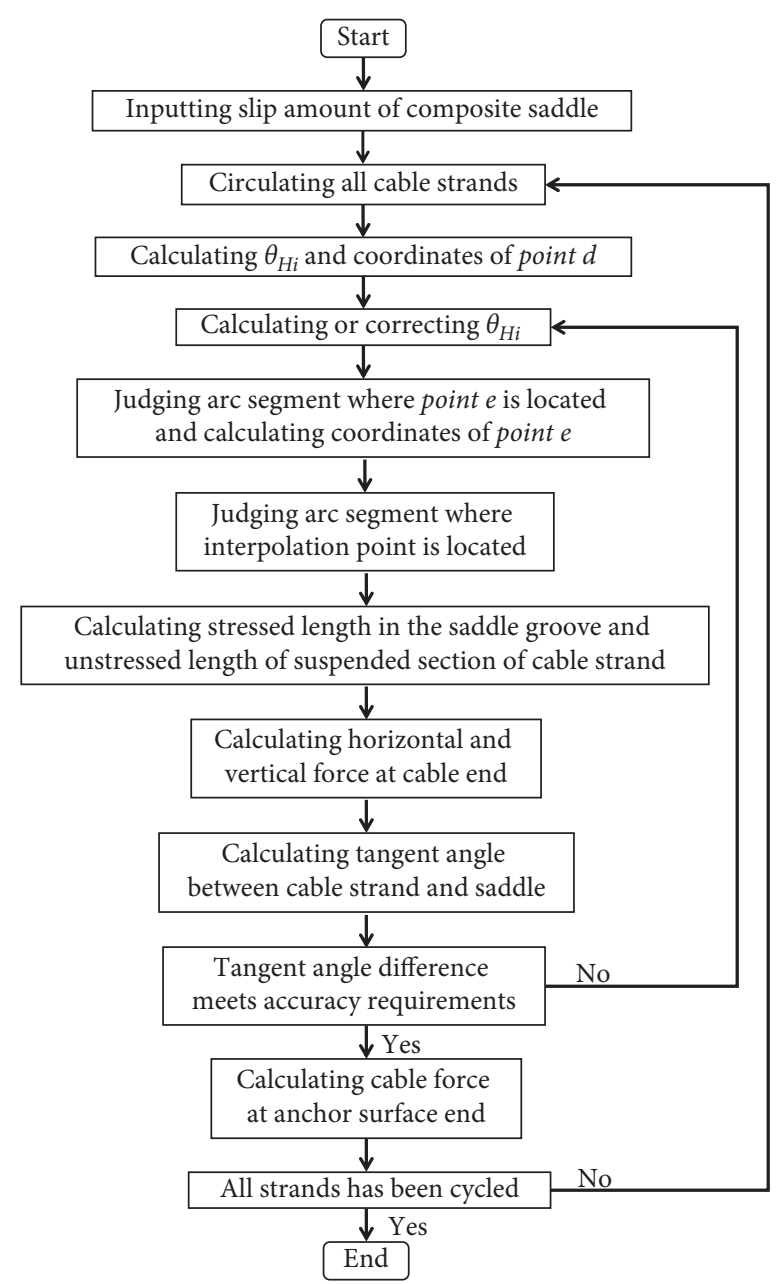

(b)

Figure 6: Calculation process of target cable force. (a) Calculation process of cable-stayed bridge phase and (b) calculation process of construction phase.

strand under the action of force. According to the field observation and calculation, during the sliding process of the composite saddle, most of Point $d$ of the cable strands are in the first circular arc saddle groove of the composite saddle, and Point $e$ is in the other circular arc saddle grooves. To ensure that the actual length calculation of the cable strands in the saddle groove has higher accuracy, the cable segment from Point $d$ to Point e needs to be divided into more interpolation points. Through the checking calculation, when it is divided into 400 segments, the calculation of cable strand space curve length has high accuracy, which can meet the actual calculation needs of the project.

\subsection{Calculation Process of a Round of Cable Strand} Adjustment. The target cable force, the initial adjustment amount, and the cable force of each sling are known. Through the calculation process of a round of adjustment of all cable strands, the slip amount of composite saddle, the strain increment of all cable strands, and the current cable force can be calculated, and the calculation process is as shown in Figure 7. If the difference between the current cable force and the target cable force does not meet the accuracy requirements, it is necessary to update the tangent point coordinates between the composite saddle and the main cable of the main span, the span of the main span, and the initial adjustment amount of all cable strands for the iterative calculation of the second round of cable strand adjustment.

\subsection{Overall Calculation Process of Strain Incremental Ad-} justment Method. After a round of cable strand adjustment calculation, the difference between the current cable force and the target cable force of most cable strands often cannot be within the required accuracy range, and multiple rounds of cable strand adjustment calculation are required. A strain incremental adjustment method is proposed to obtain the adjustment amount of the actual construction. The overall calculation process is as follows:

(1) After a round of cable strand adjustment calculation, the updated cable strand adjustment amount $\Delta l_{i}^{\prime}$, the span of main span $l^{\prime}$, and the coordinates of Point $e$ are obtained. 


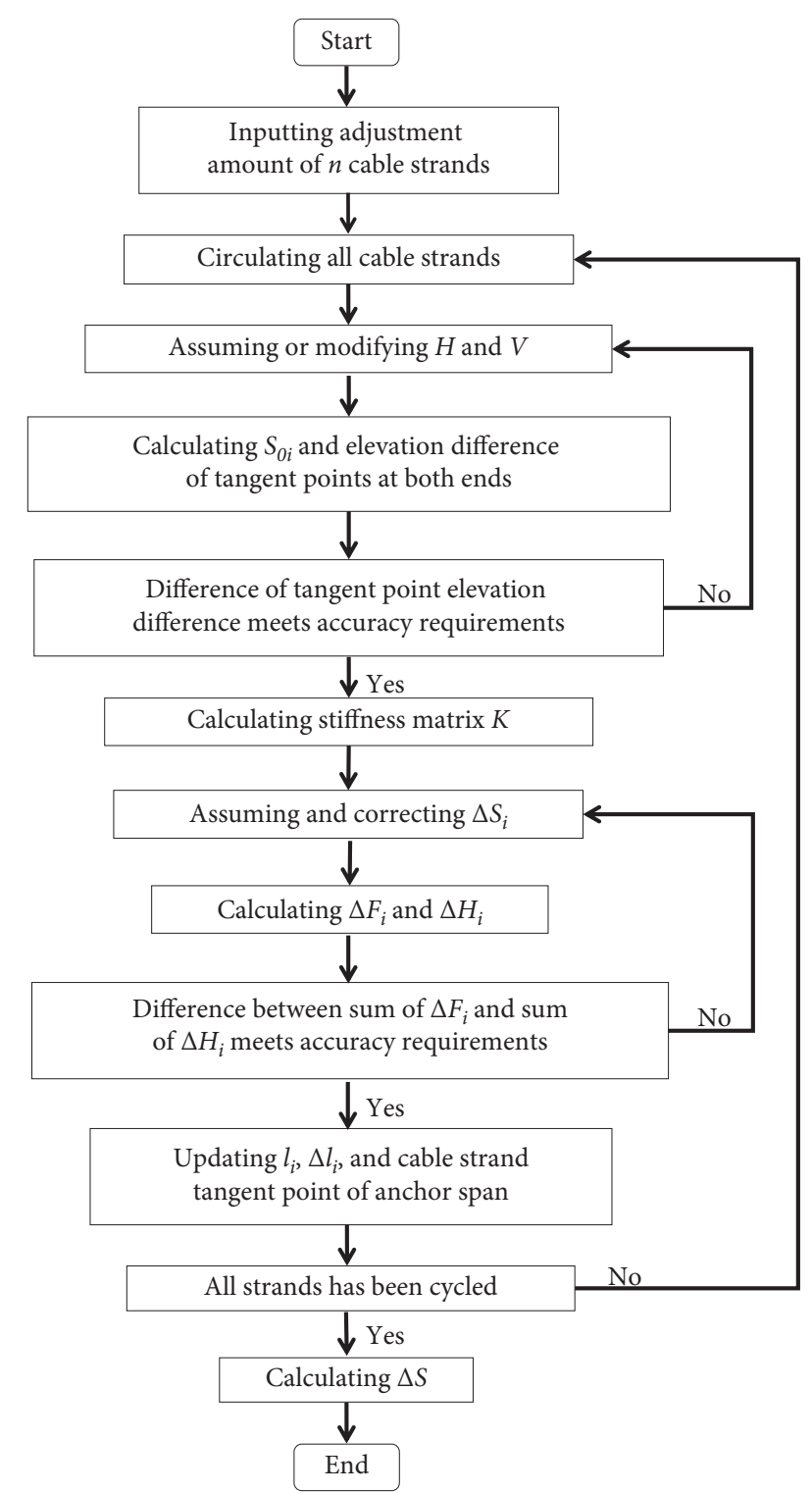

FIGURE 7: Calculation process of a round of adjustment of all cable strands.

(2) The slip amount of composite saddle after adjusting all cable strands in a round is superimposed. The actual cable force of all cable strands at the current position and the difference $\Delta T_{i}$ between the actual cable force and the target cable force are calculated, and the error accuracy $\varepsilon$ of all strands is determined.

(3) All cable strands errors meet the accuracy requirements, i.e., $\max \left|\Delta T_{i}\right| \leq \varepsilon$. If not, the cable strand adjustment is calculated again by returning to step 1 , and the sum of the slip amount of the composite saddle after a round of adjustment calculation is updated.

(4) After $m$ rounds of cable strand adjustment calculation, all cable strands errors meet the accuracy requirements. The amount of change of cable strand adjustment amount caused by strain increment in each phase is superimposed, i.e., equation (16), to obtain the adjustment amount of all cable strands in actual construction.

\section{Example Analysis}

5.1. Project Description. The Jinsha River Bridge at Hutiao Gorge of Xiangli expressway is the single-tower single-span ground-anchored suspension bridge with a main span of $766 \mathrm{~m}$. Due to the influence of topographic and geological conditions [35-40], the anchor form of Lijiang bank is designed as a gravity anchor, and the anchor form of Shangri La bank is designed as a tunnel anchor. The main cable is composed of 97 cable strands, and each cable strand is composed of 127 galvanized steel wires with a diameter of $5.4 \mathrm{~mm}$, with a tensile strength of $1770 \mathrm{MPa}$ and an elastic modulus of $2.0 \times 10^{5} \mathrm{MPa}$. The composite saddle is located between the main span and the anchor span of Shangri La bank, and the anchor span is $30 \mathrm{~m}$, overall layout is as shown in Figure 8.

5.2. Calculation and Program Verification of Target Cable Force. After the erection of the main cable, the composite saddle in the current position has occurred a slide of $82 \mathrm{~mm}$ towards the anchor span, compared with the composite saddle of the cable-stayed bridge position. Before adjusting the cable force, it is necessary to measure the initial cable force of each cable strand at the anchor surface end of the cable strand. The measured initial cable force is shown in Figure 9.

Compared with the composite saddle of the cable-stayed bridge position, the composite saddle in the pre-bias position has occurred slide of $89 \mathrm{~mm}$ towards the anchor span. The anchor span cable force is adjusted in multiple rounds so that the cable force of all cable strands approaches the theoretical value, and the composite saddle slides $7 \mathrm{~mm}$ towards the anchor span. The theoretical value is calculated by the finite element model. The actual construction adjustment amount of multiple rounds of each cable strand is superimposed. The superposition value is as shown in Figure 10, in which the positive value represents stretching and the negative value represents relaxation.

According to the field measured data and the overall structure calculation, the horizontal and vertical forces of the main cable at the main span side of the composite saddle are $159183.8 \mathrm{kN}$ and $58517.3 \mathrm{kN}$ in the cable-stayed bridge phase. When there is no external load on the main cable, the pre-bias position of the composite saddle is taken as the target position, and the target cable force can be calculated. According to the program of the calculation process at the cable-stayed bridge phase, the parameters such as the tension of the main cable, the arrangement position of the cable strand in the saddle groove, the coordinates of the anchor surface, and the measured temperature of $18.2^{\circ} \mathrm{C}$ are input, and the unstressed length from Point $b$ to the anchor point of cable strand at the current temperature can be output. The calculated unstressed length at the cable-stayed bridge phase is input. According to the program of the calculation process of the construction phase, the target cable force of the cable strand at the current temperature can be output, when the 


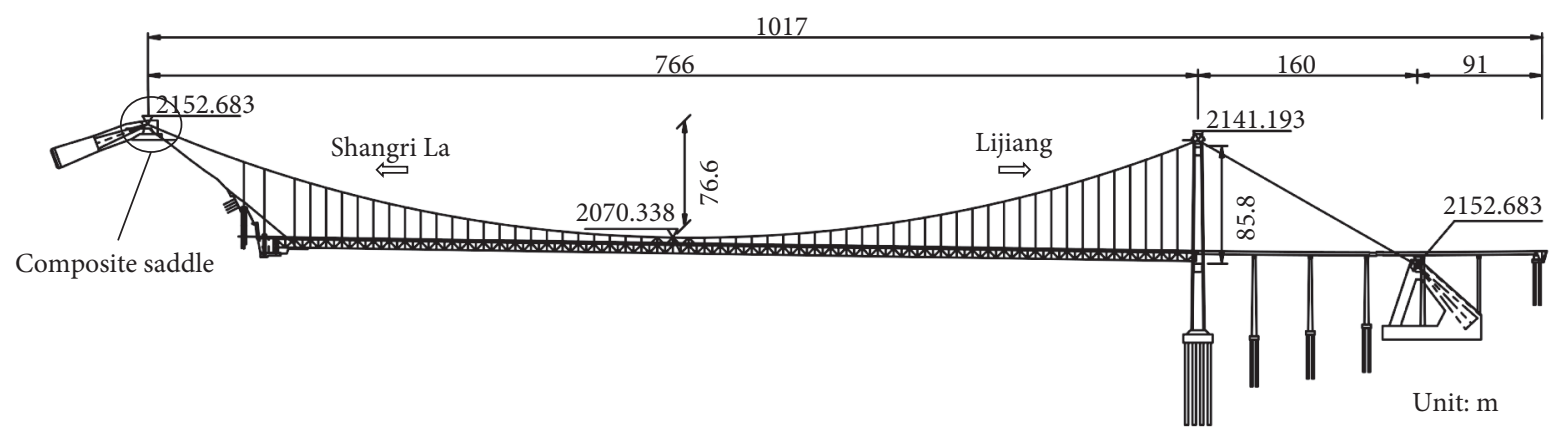

Figure 8: Overall layout of Jinsha River Bridge at Hutiao Gorge.

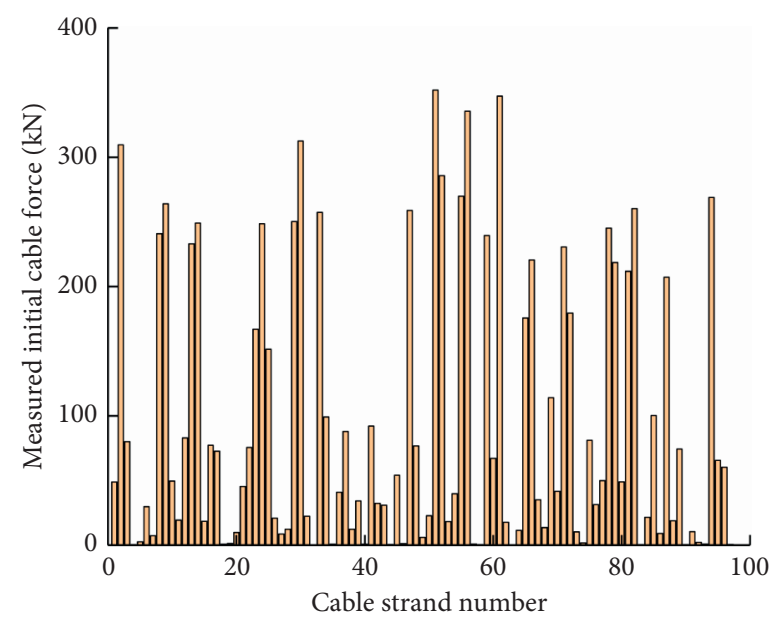

Figure 9: Measured cable force before cable strand adjustment.

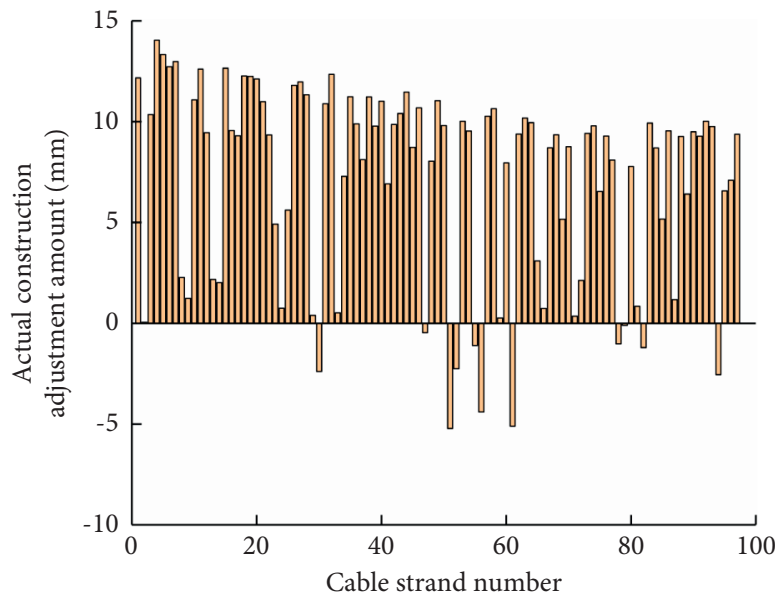

Figure 10: Actual construction adjustment of cable strand.

composite saddle is at the target position. The anchor point of the central cable strand is the coordinate origin of the anchor surface. As shown in Figure 11, the lowest layer of anchor surface cable strand is the first layer, and the uppermost layer is the 21st layer. When there is no external load on the main cable, the target cable force of the cable strand is regular, and the cable force increases gradually from the top to the bottom of the anchor surface.
By comparing the target cable force with the measured cable force after the last round of cable strand adjustment, the difference is shown in Figure 12.

It can be seen from Figure 12 that the difference after the last round of cable strand adjustment is within $2 \mathrm{kN}$, which proves that the target cable force calculated by the calculation program of the cable-stayed bridge and construction phase has high accuracy. 


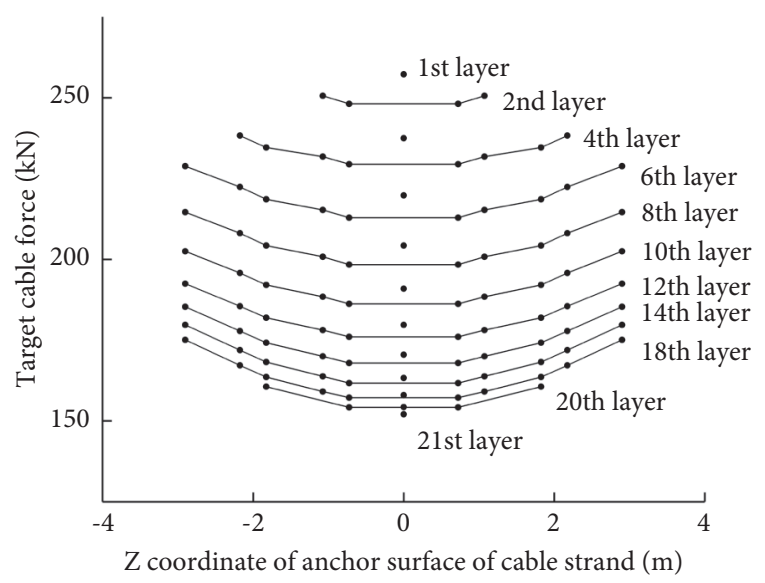

Figure 11: Target cable force.

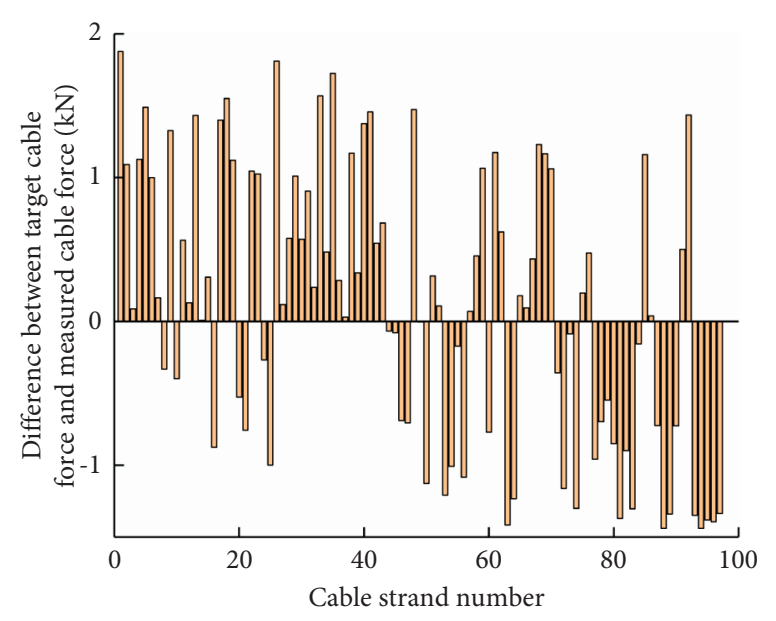

Figure 12: Difference between measured cable force and target cable force.

\subsection{Calculation and Optimization of Cable Strand} Adjustment. The superposition value of multiple rounds of actual construction adjustment amount is taken as the initial adjustment amount of cable strands, and then the cable force value after a round of cable strand adjustment is calculated. To verify the practicability of the calculation program of a round of adjustment of all cable strands, the calculated cable force calculated by a round of cable strand adjustment is compared with the measured cable force after the last round of cable strand adjustment. The difference between the measured cable force and the calculated cable force is shown in Figure 13.

It can be seen from Figure 13 that the difference of all cable strands is within $2.5 \mathrm{kN}$, and the sum of the slip amount of the composite saddle is $7.11 \mathrm{~mm}$, which verifies the practicability of the calculation program of a round of adjustment of all cable strands.

Due to the excessive adjustment of a single cable strand in the cable strand adjustment process, there will be relative slippage between cable strands. To avoid relative slippage, it is necessary to adjust all cable strands in multiple rounds. The measured cable force before the first round of cable

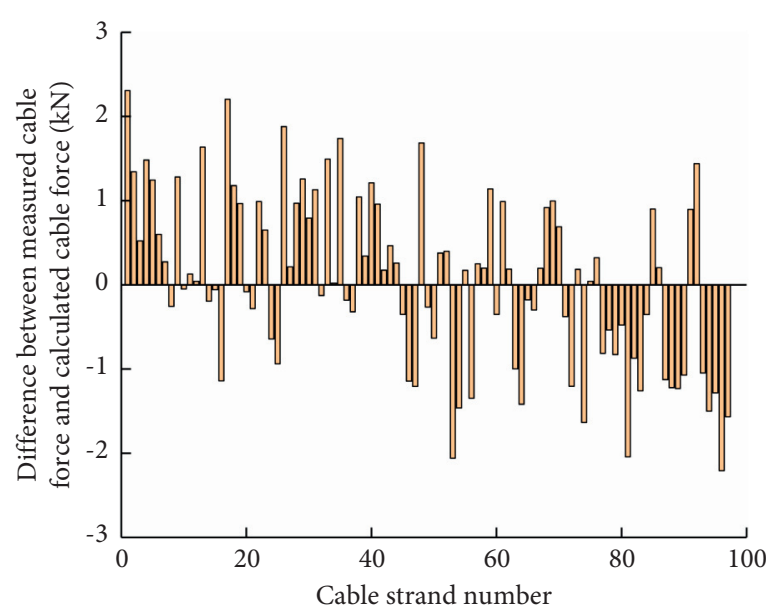

FIGURE 13: Difference between measured cable force and calculated cable force.

strand adjustment is taken as the initial value. To optimize the multiple rounds adjustment of all cable strands, the prebias position of the composite saddle is taken as the target position, and the cable force in Figure 10 is taken as the target cable force.

When the amount of change of cable force during cable strand adjustment is $50 \mathrm{kN}$, there is no relative slippage between cable strands, and there is a large safety coefficient. According to the calculation results in the previous section, the difference between the target cable force and the initial cable force is between $-175.95 \mathrm{kN}$ and $250.21 \mathrm{kN}$. The cable force adjustment difference of each round is $50 \mathrm{kN}$, and the cable strand construction adjustment is carried out continuously in 5 rounds. For cable strands with the cable force difference of more than $200 \mathrm{kN}, 200 \mathrm{kN}$ is taken as the target cable force of the first round, and the initial adjustment amount of the cable strand is calculated. For cable strands with the cable force difference of less than $200 \mathrm{kN}$, the adjustment amount is 0 , and the calculation error accuracy $\varepsilon$ is $0.1 \mathrm{kN}$. According to the strain incremental adjustment method, the adjustment amount of all cable strands, the cable force value of all cable strands, and the slip amount of the composite saddle in the first round are calculated, and the calculated cable force value of all cable strands after adjustment is taken as the initial value. Through repeating the above steps, $150 \mathrm{kN}$ is taken as the target cable force of the second round with the cable force difference of more than $150 \mathrm{kN}$, and the adjustment amount of the cable strand with the cable force difference of less than $150 \mathrm{kN}$ is set to 0 , etc. According to the strain incremental adjustment method, the adjustment amount of the cable strand and the slip amount of the composite saddle are calculated in 5 rounds, which is shown in Figures 14 and 15.

As seen in the figure above, 13, 48, 69, 85, and 97 cable strands are adjusted, respectively, in 5 rounds of cable strand adjustment. Compared with the conventional method of adjusting all cable strands in each round, the optimization method avoids excessive repeated stretching and relaxation of a single cable strand in the process of multiple rounds of cable strand adjustment, reducing the amount of 


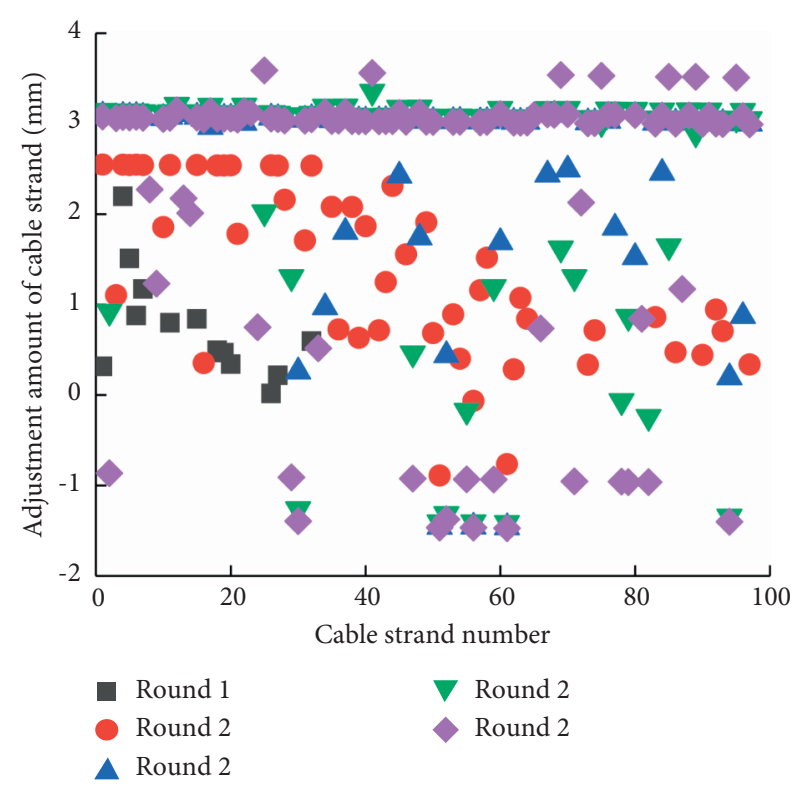

Figure 14: Adjustment amount of cable strand of 5 rounds.

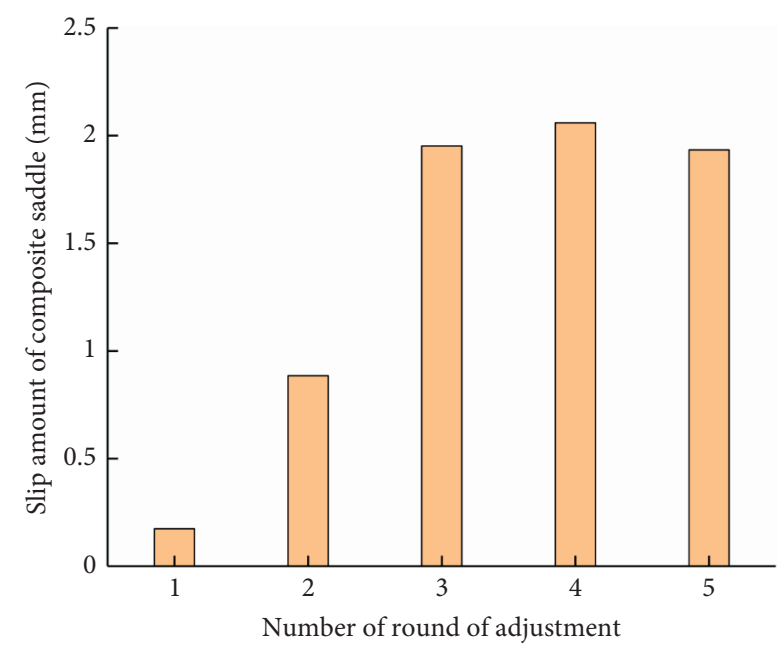

Figure 15: Slip amount of composite saddle.

construction adjustment, and it also avoids the relative slippage between cable strands in the process of cable strand adjustment. The superposition value of the slip amount of the composite saddle after the 5 rounds of cable strand adjustment is $7.0038 \mathrm{~mm}$, which shows that the composite saddle can return to the target pre-bias position through cable force adjustment.

\section{Conclusion}

For the cable force adjustment of composite saddle anchor span of single-tower single-span ground-anchored suspension bridge, a strain incremental adjustment method is proposed. The calculation of theoretical target cable force and the cable force adjustment is studied by the analytical calculation method. The Jinsha River Bridge at Hutiao Gorge is taken as the research object, and the following conclusions are shown:
(1) A strain incremental adjustment method of cable force of composite saddle anchor span of singletower single-span ground-anchored suspension bridge is proposed. Under the premise of ignoring the influencing factors such as the construction environment, this method can adjust the cable force of anchor span cable strand to the target cable force in a round theoretically and can achieve the purpose of precise adjustment. Compared with the conventional method, it improves the cable strand adjustment efficiency.

(2) The target cable force value of cable strand, the calculated cable force value of cable strand, and the slip amount of composite saddle are calculated by this method. By comparing the calculated values with the measured values, the practicability of this method is verified.

(3) To avoid the relative slippage between cable strands in the process of cable strand adjustment, the adjustment amount of multiple rounds of cable strands is optimized. Compared with the conventional method of adjusting all cable strands in each round, this optimization method avoids excessive repeated stretching and relaxation of a single cable strand in the process of multiple rounds of cable strand adjustment and reduces the amount of construction adjustment.

(4) Before the suspension bridge is opened to traffic, it is necessary to test the cable force of the composite saddle anchor span under the cable-stayed bridge state. If the difference between the target cable force and the measured cable force does not meet the requirements of cable strand adjustment accuracy, the target cable force and the actual adjustment amount can be calculated by inputting the sling force at each cable clamp under the current state.

\section{Data Availability}

The data used to support the findings of this study are included within the article.

\section{Conflicts of Interest}

The authors declare that there are no conflicts of interest regarding the publication of this study.

\section{Acknowledgments}

This study was sponsored by the National Natural Science Foundation of China (no. 51669009) and the Key Research and Development Projects of Science and Technology Department of Yunnan Province (no. 2018BC0008).

\section{References}

[1] J. W. Jung, D. J. Moon, J. W. Jung, S. K. Ro, and J. H. Park, A Correlation Analysis Regarding the Temperature Effect for a 
Suspension Bridge, Springer International Publishing, New York, NY, USA, 2015.

[2] J. Nie, M. Tao, and J. Fan, "Research on cable anchorage systems for self-anchored suspension bridges with steel box girders," Journal of Bridge Engineering, vol. 16, no. 5, pp. 633-643, 2011.

[3] X. Wang, W. Yang, X. Zhang, and P. Zhu, "Experimental and numerical study on a novel cable anchorage system to improve the maintainability of suspension bridges," Structure, vol. 27, pp. 2126-2136, 2020.

[4] J. Lei, Suspension Bridge Design, Communications Press, Beijing, China, 2002.

[5] D. H. Choi, S. G. Gwon, and H. S. Na, "Simplified analysis for preliminary design of towers in suspension bridges," Journal of Bridge Engineering, vol. 19, no. 3, 2013.

[6] J. Li, A. Li, and M. Q. Feng, "Sensitivity and reliability analysis of a self-anchored suspension bridge," Journal of Bridge Engineering, vol. 18, no. 8, pp. 703-711, 2013.

[7] K. Mei, S. Sun, G. Jin, and Y. Sun, "Static and dynamic mechanical properties of long-span cable-stayed bridges using CFRP cables," Advances in Civil Engineering, vol. 2017, Article ID 6198296, 11 pages, 2017.

[8] H. Zhang, N. Sun, P. Wang, M. Liu, and Y. Li, "Optimization of cable force adjustment in cable-stayed bridge considering the number of stay cable strand adjustment," Advances in Civil Engineering, vol. 2020, Article ID 4527309, 20 pages, 2020.

[9] Z. Lu, C. Wei, M. Liu, and X. Deng, "Risk assessment method for cable system construction of long-span suspension bridge based on cloud model," Advances in Civil Engineering, vol. 2020, Article ID 4527309, 9 pages, 2020.

[10] D. Wang, Y. Li, and Y. Liu, "Analysis of refinement control of anchor cable tension for long-span suspension bridge," China Journal of Highway and Transport, vol. 27, no. 1, pp. 51-56, 2014.

[11] R. Shen, S. Xue, J. Ma, and B. Liu, "Experimental study of composite saddle of a single-tower single-span earth-anchored suspension bridge," Bridge Construction, vol. 49, no. 5, pp. 15-20, 2019.

[12] X. Luo, R. Xiao, and H. Xiang, "Analysis study of anchor span strand for suspension bridges," Journal of Highway and Transportation Resecircular arch and Development, vol. 21, no. 12, pp. 45-49, 2004.

[13] D. Qi, R. Shen, and M. Tang, "Study and application of anchorage-anchor span element for suspension bridge," Journal of Highway and Transportation Resecircular arch and Development, vol. 28, no. 2, pp. 82-92, 2011.

[14] S. Chen, C. Li, and H. Ke, "Strand tension calculation and monitoring of anchor span during construction of suspension bridges," Journal of Transport Science and Engineering, vol. 28, no. 4, pp. 32-36, 2012.

[15] H. Tan and R. Xiao, "Strand tension in anchor-span suspension bridge at different temperatures," Journal of South China University of Technology: Natural Science Edition, vol. 38, no. 9, pp. 118-122, 2010.

[16] M. M. Hassan, A. O. Nassef, and A. A. El Damatty, "Determination of optimum post-tensioning cable forces of cablestayed bridges," Engineering Structures, vol. 44, pp. 248-259, 2012.

[17] H. K. Byeong and P. Taehyo, "Estimation of cable tension force using the frequency-based system identification method," Journal of Sound and Vibration, vol. 304, no. 3, pp. 660-676, 2007.
[18] X. Zhang, R. Shen, M. Tang, and H. Ye, "Accurate calculation and adjustment methods for cable forces of anchor-span strands of suspension bridges," Journal of Southwest Jiaotong University, vol. 47, no. 4, pp. 551-557, 2012.

[19] H. Tan, Z. Hou, Z. Qiu, J. Ji, and D. Chen, "The USGT method for suspender tensioning of self-anchored suspension bridges," Advances in Civil Engineering, vol. 2021, Article ID 6619924, 10 pages, 2021.

[20] Y. Sun, L. Zhang, and Z. Li, "Analysis of parameters influencing suspender target cable forces of self-anchored suspension bridge," Bridge Construction, vol. 45 , no. 4, pp. $69-74$, 2015.

[21] B. Atmaca, T. Dede, and M. Grzywinski, "Optimization of cables size and prestressing force for a single pylon cablestayed bridge with Jaya algorithm," Steel and Composite Structures, vol. 34, no. 6, pp. 853-862, 2020.

[22] Z. Wang, N. Zhang, X. Du, S. Wang, and Q. Sun, "Multiobjective optimization of cable forces and counterweights for universal cable-stayed bridges," Journal of Advanced Transportation, vol. 2021, Article ID 6615746, 13 pages, 2021.

[23] B. Asgari, S. A. Osman, and A. Adnan, "A new multiconstraint method for determining the optimal cable stresses in cablestayed bridges," The Scientific World Journal, vol. 2014, Article ID 503016, 9 pages, 2014.

[24] A. Andreu, L. Gil, and P. Roca, "A new deformable catenary element for the analysis of cable net structures," Computers \& Structures, vol. 84, no. 29, pp. 1882-1890, 2006.

[25] W. Zhang, G. Tian, and Z. Liu, "Analytical study of uniform thermal effects on cable configuration of a suspension bridge during construction," Journal of Bridge Engineering, vol. 24, no. 11, 2016.

[26] M.-Y. Kim, M.-R. Jung, and M. M. Attard, "Unstrained length-based methods determining an optimized initial shape of 3-dimensional self-anchored suspension bridges," Computers \& Structures, vol. 217, no. 5, pp. 18-35, 2019.

[27] Q. Gao, N. Hong, B. Guo, Y. Liu, and Q. Ma, "Calculation method for length of main cable at saddle in long-span suspension bridge," Journal of Harbin Institute of Technology, vol. 52, no. 9, pp. 57-62, 2020.

[28] J. He, C. Li, H. Ke et al., "A simplified calculation method of length adjustment of datum strand for the main cable with small sag," Advances in Civil Engineering, vol. 2019, Article ID 6075893, 8 pages, 2019.

[29] W.-m. Zhang, L.-y. Shi, L. Li, and Z. Liu, "Methods to correct unstrained hanger lengths and cable clamps' installation positions in suspension bridges," Engineering Structures, vol. 171 , no. 5, pp. 202-213, 2018.

[30] X. Luo, R. Xiao, and H. Xiang, "Cable element based on exact analytical expressions," Journal of Tongji University: Natural Science, vol. 33, no. 4, pp. 445-450, 2005.

[31] P. Lu, J. Chen, J. Zhong, and P. Lu, "Optimization analysis model of self-anchored suspension bridge," Mathematical Problems in Engineering, vol. 2014, Article ID 403962, 8 pages, 2014.

[32] S. G. Gwon and D. H. Choi, "Continuum model for static and dynamic analysis of suspension bridges with a floating girder," Journal of Bridge Engineering, vol. 23, no. 10, 2018.

[33] C. Zhang, Q. Guo, and X. Zhang, "Determination of the strain-free configuration of multi-span cable," Shock and Vibration, vol. 2015, Article ID 890474, 6 pages, 2015.

[34] H. Wang, S. Qin, Z. Zhang, C. Huang, and W. Xu, "The basic differential equations of self-anchored cable-stayed suspension bridge," Mathematical Problems in Engineering, vol. 2010, Article ID 805195, 12 pages, 2010. 
[35] X. Li, K. Peng, J. Peng, and D. Hou, "Experimental investigation of cyclic wetting-drying effect on mechanical behavior of a medium-grained sandstone," Engineering Geology, vol. 293, Article ID 106335, 2021.

[36] X. Li, K. Peng, J. Peng, and H. Xu, "Effect of cyclic wettingdrying treatment on strength and failure behavior of two quartz-rich sandstones under direct shear," Rock Mechanics and Rock Engineering, vol. 54, no. 11, pp. 5953-5960, 2021.

[37] Y. Wang, B. Zhang, B. Li, and C. Li, "A strain-based fatigue damage model for naturally fractured marble subjected to freeze-thaw and uniaxial cyclic loads," International Journal of Damage Mechanics, vol. 33, no. 9, pp. 1305-1323, 2021.

[38] M. Gao, J. Xie, Y. Gao et al., "Mechanical behavior of coal under different mining rates: a case study from laboratory experiments to field testing," International Journal of Mining Science and Technology, vol. 31, no. 5, pp. 825-841, 2021.

[39] M. Gao, J. Xie, J. Guo, Y. Lu, Z. He, and C. Li, "Fractal evolution and connectivity characteristics of mining-induced crack networks in coal masses at different depths," Geomechanics and Geophysics for Geo-Energy and Geo-Resources, vol. 7, no. 1, 2021.

[40] Z. Tao, C. Zhu, M. He, and M. Karakus, "A physical modelingbased study on the control mechanisms of negative Poisson's ratio anchor cable on the stratified toppling deformation of anti-inclined slopes," International Journal of Rock Mechanics and Mining Sciences, vol. 138, Article ID 10335, 2021. 